\title{
Cancer in the electric power industry
}

\author{
S TÖRNQVIST, ${ }^{1}$ S NORELL, ${ }^{2}$ A AHLBOM, ${ }^{2}$ AND B KNAVE ${ }^{1}$
}

From the Department of Occupational Neuromedicine, ${ }^{1}$ National Board of Occupational Safety and Health, Solna, and Department of Epidemiology, ${ }^{2}$ National Institute of Environmental Medicine, Stockholm, Sweden

ABSTRACT A cohort study of 3358 power linesmen and 6703 power station operators classified in the $\vec{\circ}$ 1960 population census in Sweden was undertaken. The cancer incidence between 1961 and $1979 \overrightarrow{\vec{\omega}}$ was calculated in relation to all male blue collar workers. The relative risk of cancer (all sites) was $\omega_{\circ}^{\omega}$ $1 \cdot 1,(1 \cdot 0-1 \cdot 2,90 \%$ confidence limit) in the group of power linesmen and $1.0(0.9-1 \cdot 0)$ for power $\stackrel{\mathbb{D}}{\mathbb{D}}$ station operators. No consistent excess risk of leukaemia or brain tumour was found in the two occupational groups. In both groups a tendency towards an excess risk of cancer of the urinary organs was found.

In the industrialised world high voltage electricity has been distributed commercially for over a century. It has been supposed that the only associated health risks were burns from fire or explosions and electrocution. Over the past ten years, however, several reports have suggested a variety of biological effects from electrical and magnetic fields associated with the transmission and use of electricity. ${ }^{1}$ Quite recently interest has focused on the incidence of cancer in children and adults living in houses near electric power lines. In three case-control studies an excess risk of cancer was reported, ${ }^{2-4}$ but one study found no such excess risk. ${ }^{5}$ There is some evidence that occupational exposure to electrical and magnetic fields may be associated with increased risks of cancer, particularly leukaemia, ${ }^{6-11}$ but so far the evidence has not been convincing. ${ }^{12-14}$ We have studied the incidence of cancer in the male occupational groups of power linesmen and power station operators in the electric power industry in Sweden.

\section{Material and methods}

In Sweden every living person is given an individual identification number at birth which makes it possible to link the census to medical registries. A cancer environment registry ${ }^{15}$ has been created through a record linkage between the cancer register for the period 1961-79 and the 1960 census. The cancer environment register provides information about the number of cases of cancer for different sites according to occupation, industry, sex, age, and county. The 1960 census provides information about the number of individuals in the population (close to eight million) in 1960 by the same variables.

Accepted 5 August 1985
The study was based on Swedish born men aged $\vec{N}$ $20-64$ at the time of the census. According to the 1960 음 census there were 3358 power linesmen and $6703_{-}^{-}$ power station operators in the electric power industry. The cancer environment register recorded 236 cases of $\frac{\widetilde{\partial}}{\partial}$ cancer among power linesmen and 463 among power station operators. The observed number of cases for $\stackrel{\infty}{\infty}$ each of the different sites was compared with the cor-? responding expected number, which was based on the cumulative incidence for all $\mathbf{9 8 6 4 0 8}$ men classified as blue collar workers according to the census. The ex- $\frac{\overline{0}}{\mathrm{O}}$ pected number was calculated after stratification for age in five year groups and for county. The com- $\mathbb{\perp}$ parison was based on the standardised morbidity ratio $\overrightarrow{\vec{S}}$ (SMR) and $90 \%$ confidence intervals were assessed according to Rothman and Boice. ${ }^{16}$

\section{Results}

The observed and expected numbers of cancers are presented in the table with the SMR values and 3 confidence limits. For none of the specific cancer sites, nor for all cancers combined, did the lower confidence $\frac{\rho}{3}$ limit exceed unity. In addition none of the SMR values was marginally high. For power linesmen the $\frac{}{\supset}$ SMR, regardless of site, was $1 \cdot 1$, whereas for power $\frac{7}{2}$ station operators it was $\mathbf{1} \cdot 0$. Among power linesmen the SMR for leukaemia was 1.3 and among power $N$ station operators $1 \cdot 0$. In the two occupational groups combined there were 26 cases of leukaemia represent- 0 ing several histopathological groups. None of these $\mathcal{W}$ subgroups with leukaemia, however, showed an ex- -2 cess risk in either occupational group under study. For acute myeloid leukaemia one case was observed $\mathbb{\Phi}$ among power linesmen and three among power sta-? tion operators. The SMR value for tumours of the $\vec{T}$ nervous system was 1.5 among power linesmen and $\frac{\vec{\Phi}}{\oplus}$ 1.0 among power station operators. There were five $\bigcirc$ 
$S M R$ for different cancers among male power linesmen and power station operators during a 19 year follow up. Stratification by age and county

\begin{tabular}{|c|c|c|c|c|c|c|c|c|}
\hline \multirow{2}{*}{$\begin{array}{l}\text { Cancer site } \\
\text { (ICD code, } 7 \text { th rev) }\end{array}$} & \multicolumn{4}{|c|}{ Power linesmen $(n=3358)$} & \multicolumn{4}{|c|}{ Power station operators $(n=6703)$} \\
\hline & Obs & $\operatorname{Exp}$ & $S M R$ & (90\% Conf limits) & Obs & $\operatorname{Exp}$ & $S M R$ & (90\% Conf limits) \\
\hline $\begin{array}{l}\text { Stomach (151) } \\
\text { Colon (153) } \\
\text { Rectum (154) } \\
\text { Pancreas (157) } \\
\text { Larynx (161) } \\
\text { Lung, trachea (162) } \\
\text { Prostate (177) } \\
\text { Testis (178) } \\
\text { Kidney (180) } \\
\text { Urinary organs excluding kidney (181) } \\
\text { Skin excluding melanoma (191) } \\
\text { Nervous system (193) } \\
\text { Leukaemia (204) }\end{array}$ & $\begin{array}{r}25 \\
15 \\
8 \\
7 \\
3 \\
17 \\
41 \\
1 \\
15 \\
18 \\
8 \\
13 \\
10\end{array}$ & $\begin{array}{r}20 \cdot 9 \\
15 \cdot 1 \\
11 \cdot 6 \\
9 \cdot 3 \\
2.9 \\
25 \cdot 9 \\
35 \cdot 1 \\
1 \cdot 6 \\
11 \cdot 3 \\
14 \cdot 5 \\
5 \cdot 4 \\
8 \cdot 7 \\
8 \cdot 0\end{array}$ & $\begin{array}{l}1 \cdot 2 \\
1 \cdot 0 \\
0 \cdot 7 \\
0 \cdot 8 \\
1 \cdot 0 \\
0 \cdot 7 \\
1 \cdot 2 \\
0 \cdot 6 \\
1 \cdot 3 \\
1 \cdot 2 \\
1 \cdot 5 \\
1 \cdot 5 \\
1 \cdot 3\end{array}$ & 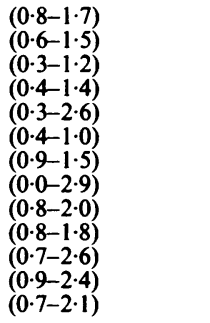 & $\begin{array}{r}42 \\
32 \\
21 \\
19 \\
10 \\
40 \\
76 \\
6 \\
29 \\
40 \\
12 \\
17 \\
16\end{array}$ & $\begin{array}{r}44 \cdot 0 \\
32 \cdot 1 \\
24 \cdot 2 \\
19.5 \\
6 \cdot 1 \\
56 \cdot 6 \\
80.0 \\
3 \cdot 2 \\
23 \cdot 0 \\
30.5 \\
11.6 \\
17.5 \\
16.6\end{array}$ & $\begin{array}{l}1.0 \\
1.0 \\
0.9 \\
1.0 \\
1.6 \\
0.7 \\
1.0 \\
1.8 \\
1.3 \\
1.3 \\
1.0 \\
1.0 \\
1.0\end{array}$ & $\begin{array}{l}(0.7-1 \cdot 2) \\
(0.7-1 \cdot 3) \\
(0.6-1 \cdot 2) \\
(0.6-1 \cdot 4) \\
(0.9-2 \cdot 7) \\
(0.5-0.9) \\
(0.8-1 \cdot 1) \\
(0.8-3 \cdot 6) \\
(0.9-1 \cdot 7) \\
(1.0-1 \cdot 7) \\
(0.6-1 \cdot 7) \\
(0.6-1 \cdot 5) \\
(0.6-1 \cdot 5)\end{array}$ \\
\hline All sites $(140-204)$ & 236 & $221 \cdot 5$ & $1 \cdot 1$ & $(1 \cdot 0-1 \cdot 2)$ & 463 & $472 \cdot 7$ & $1 \cdot 0$ & $(0 \cdot 9-1 \cdot 0)$ \\
\hline
\end{tabular}

cases of glioblastoma in each occupational group (3.9 and 7.9 expected). Hence we found no consistent excess risk of leukaemia or brain tumours in our groups. In both occupational groups, however, there was a tendency towards an excess risk of cancer of the kidney and of other urinary organs (see table).

\section{Discussion}

The levels and duration of individual exposure to electrical and magnetic fields, are not known in the occupational groups studied here. For instance, only a few in our groups have worked at $400 \mathrm{kV}$ substations and powerlines, the highest tension in use in Sweden today. It should also be emphasised that both groups are exposed to various chemicals at work. Power station operators, for example, are exposed to lubricating oil, solvents, polychlorinated biphenyls, and exhaust gas from internal combustion engines, and power linesmen are exposed to chemicals such as creosote, lead, isocyanates, and silicon.

Mobility between occupations might influence the results, since the cohorts were defined from the occupation the subject reported at the time of the census. Nevertheless, the groups in our study are known to be quite stable in their occupations. Individual variations in the levels and duration of exposure would include subjects with little or no exposure in the exposed groups, and would bias the SMR values towards unity.

Previous studies have suggested an excess incidence $^{6-8}$ and mortality ${ }^{9-11}$ from cancer and leukaemia, especially acute myeloid leukaemia, in several groups of workers loosely defined as "electrical workers" in the electric and electronics industries. The definitions of the exposed groups vary considerably between these studies and the results are difficult to compare.

Recently a case-control study suggested that exposure to electrical and magnetic fields was associated with an excess of glioma and astrocytoma. ${ }^{17}$ Our results, however, do not support an association between exposure to electrical and magnetic fields and leu- kaemia or brain tumours. Nevertheless, an unexpected tendency towards raised risks of cancer of the kidney and other urinary organs was found in both occupational groups.

This study was supported by grants from the Swedish Work Environment Fund.

\section{References}

${ }^{1}$ World Health Organisation. Extremely low frequency (ELF) fields. Geneva: WHO, 1984. (Environmental Health Criteria 35.)

${ }^{2}$ Wertheimer N, Leeper E. Electrical wiring configurations and childhood cancer. Am J Epidemiol 1979;109:273-84.

${ }^{3}$ Wertheimer N, Leeper E. Re: Electrical wiring configurations and childhood leukemia in Rhode Island. $A m J$ Epidemiol 1980;112:167-8.

${ }^{4}$ Wertheimer N, Leeper E. Adult cancer related to electrical wires near the home. Int J Epidemiol 1982;11:354-5.

${ }^{5}$ Fulton JP, Cobb S, Preble L, Leone L, Forman E. Electrical wiring configurations and childhood leukemia in Rhode Island. Am J Epidemiol 1980;111:292-6.

${ }^{6}$ Coleman M, Skeet R. Leukaemia incidence in electrical workers. Lancet 1983;i:982-3.

${ }^{7}$ Pearce NE, Sheppard RA, Howard JK, Fraser J, Lilley BM. Leukaemia in electrical workers in New Zealand. Lancet 1985;i:811-2.

${ }^{8}$ Wright WE, Peter JM, Mack TM. Leukaemia in workers exposed to electrical and magnetic fields. Lancet 1982;ii:1160-1.

${ }^{9}$ McDowell ME. Leukaemia mortality in electrical workers in England and Wales. Lancet 1983;i:246.

${ }^{10}$ Milham S Jr. Mortality from leukemia in workers exposed to electrical and magnetic fields. $N$ Engl J Med 1982;307:249.

${ }^{11}$ Milham S Jr. Silent keys: leukaemia mortality in amateur radio operators. Lancet 1985; i:812.

12 Bonell JA. Leukemia and electrical workers. Lancet 1983;i:1168.

${ }^{13}$ Anonymous. Electromagnetism and cancer (Ed). Lancet 1983;i:224.

${ }^{14}$ Liburdy RP. Carcinogenesis and exposure to electrical and magnetic fields. $N$ Engl J Med 1982;307:1402.

${ }^{15}$ Wicklund K, Einhorn J, Wennstrom G, Rapaport E. A Swedish cancer-environment register available for research. Scand $J$ Work Environ Health 1981;7:64-7.

${ }^{16}$ Rothman KJ, Boice JD. Epidemiologic analysis with a programmable calculator. Washington: Printing Office, 1979. (DHEW publication No (NIH) 79-1649.)

${ }^{17}$ Lin RS, Dischinger PC, Conde J, Farrell KP. Occupational exposure to electromagnetic fields and the occurrence of brain tumours. J Occup Med 1985;6:413-9. 